\title{
Knowledge and attitudes of health professionals towards pressure ulcers at a rehabilitation hospital: a cross-sectional study
}

\author{
Bayan Kaddourah', Amani K Abu-Shaheen² and Mohamad Al-Tannir ${ }^{2 *}$
}

\begin{abstract}
Background: Pressure ulcers are common conditions among hospitalized patients and impose substantial burden on patients and their caregivers. To assess the knowledge and attitudes of health professionals towards PUs prevention. Methods: A cross-sectional study was performed in the rehabilitation hospital at King Fahad Medical City, Riyadh, Saudi Arabia in 2014. The study population consisted of nurses, physical therapists, occupational therapists, and physical medicine rehabilitation physicians who have a minimum of at least one year of clinical practice. The survey that was created for use in this study consisted of demographic characteristics, Pressure Ulcers Knowledge Test and Staff Attitude Scale.
\end{abstract}

Results: The survey was completed by 105 participants of the 120 total eligible staff. The mean knowledge score of correct answers from all participants was $34.1 \pm 4.8$ (71.5 \%). Only $77(73.3 \%)$ participants had a mean knowledge score of $\geq 70 \%$. The mean attitude score was 30.5 (56.5\%). The study revealed that age and profession factors had a significant relationship with participants' mean knowledge of PUs prevention $(P<0.001)$, $(P<0.001)$ respectively. Moreover, $101(98.1 \%)$ participants are concerned about PUs prevention in their practices. While, $11(10.7 \%)$ of participants believe that PUs prevention is a time consuming procedure.

Conclusions: The present study assessed the current knowledge and attitudes of health professionals regarding PUs prevention in an acute rehabilitation hospital. The majority of participants had an average level of knowledge and exhibited unsatisfactory attitudes towards PUs prevention. Increased health professionals awareness may improve their attitudes towards PUs prevention.

Keywords: Attitudes, Knowledge, Pressure Ulcers, Quality indicator

\section{Background}

Pressure ulcers (PUs) are common conditions among hospitalized patients and impose substantial burden on patients and their caregivers. [1, 2]. Almost 1.7 million patients develop PUs per year [3]. Considerable variability in the incidence of PUs between developed and developing countries exists, with an estimated incidence

\footnotetext{
* Correspondence: maltannir@kfmc.med.sa

${ }^{2}$ Research Center, King Fahad Medical City, P.O Box 5904611525 Riyadh, Saudi Arabia

Full list of author information is available at the end of the article
}

rate of PUs of $8.3 \%$ to $25.1 \%$ in developed countries, and $2.1 \%$ to $31.3 \%$ in developing countries [4-6].

The incidence of PUs has become a universally known quality indicator in the hospital settings that the patients' quality of life, increases hospital expenses and has an adverse effect on achieving goals of care so much so that their occurrence reflects the quality of care $[7,8]$. Thus, the treatment and prevention of ulcers should be considered as a priority, especially where patients are at high risk; such as patients in rehabilitation centers [9].

Lack of knowledge and skills in PUs prevention contributes substantially to the occurrence or deterioration 
of PUs [10]. Although evidence-based guidelines for the prevention of PUs have been developed extensively and have been supported globally, the problem is still widely spread in health care facilities around the world.

Knowledge, attitudes and skills are necessary to provide effective health care. Literature about the knowledge of health care providers towards PUs prevention is inconsistent. Some studies reveal that the overall knowledge is appropriate while others show that the knowledge about PUs is adequate [11, 12]. Also, despite the positive attitude towards PUs prevention [13], various studies have revealed a gap between theory and practice [3, 14, 15]. Within Saudi healthcare professionals, there is a scarcity of information regarding PUs. Considering the fact that better knowledge and attitudes result in better health care, the entire concerned disciplines should be aware, well informed and proficient at the clinical practice guidelines in order to reduce PUs.

Therefore, this study was undertaken to assess the knowledge and attitudes of the health professionals regarding PUs prevention in an acute rehabilitation hospital.

\section{Methods}

\section{Study design}

A cross-sectional study was conducted at the rehabilitation hospital at King Fahad Medical City (KFMC), Riyadh, Saudi Arabia in 2014.

\section{Study population}

The study population comprised of all the nurses, physical therapists (PT), occupational therapists (OT), and physical medicine in rehabilitation (PMR) of both genders from the rehabilitation hospital that work directly with adult patients and have at least one year of clinical experience.

\section{Recruitment}

Participants were invited for the study by an invitation letter given to the all eligible staff at the rehabilitation hospital. Along with the invitation letter, a copy of the questionnaire and a cover page describing the aim of the study, voluntary participation of the staff and contact information. A trained research coordinator handed the questionnaire to the participants and they were asked to answer the questionnaire and return it back to the research coordinator immediately.

\section{Survey tools}

The PUs prevention survey developed for use in this study consisted of demographic characteristics that included gender, age, years of clinical experience, level of education, and profession. In addition, the study included a survey of the knowledge and attitudes of the participants about prevention of PUs.

Pressure Ulcer Knowledge Test (PUKT) was used to measure participants' level of knowledge and recommendations for PUs prevention. This test is based on the recommendations proposed in international guidelines and comprises of 47-items to examine the knowledge of participants' on PUs prevention, staging, and wound description. The participants were instructed to select an answer True, False or I Do Not Know. Each correct answer was considered one point. Correct answers corresponding to true assertions were answered with " $\mathrm{T}$ " and incorrect ones answered with "F". For incorrect or "NK" answers, the score was zero. The maximum score on the test was 47 and an average knowledge score of $\geq 70 \%$ was considered satisfactory in this study. However, in the original study, participants who achieved $90 \%$ or more of the correct answers were considered to have adequate knowledge [12]. The Staff Attitude Scale was used to obtain feedback on the attitudes of clinical staff regarding PUs prevention. The scale was designed by Moore and Price, it uses a 5-point scoring system ranging from strongly agree to strongly disagree [13]. To score, we assigned a numeric value to each response. For example, for "strongly disagree" $=5$, "disagree" $=4$, and so on. However, questions $1,6,7$, and 11 were reverse scored. For example, "strongly disagree" $=1$, and so on. The scores ranged from 11 (most negative attitudes) to 55 (most positive attitudes).

\section{Ethical considerations}

Ethical approval was obtained from the Institutional Review Board at KFMC. Participants who met the inclusion criteria were asked to participate in this study; those who agreed to take part gave written informed consent.

\section{Statistical analysis}

All data was entered into and analyzed using SPSS version 22.0 software (SPSS Inc., Chicago, IL, USA). Categorical variables like profession, age group, level of education, and years of clinical experience were presented as numbers and percentages. Whereas, mean knowledge and attitude score of PUs prevention were expressed as Mean \pm SD. Chi-square test, ANOVA and independent sample t-test were used as per condition of categories of variable to determine the mean knowledge score of PUs prevention with respect to the general characteristics of participants. P - Value of less than 0.05 was considered as statistically significant.

To improve power, we collapsed the Likert scale responses into two variables: combination of ("strongly agree" and "agree") and combination of ("uncertain", "disagree" and "strongly disagree"). 


\section{Results}

The survey was completed by 105 participants of the 120 total eligible staff who provide direct bedside care for patients from the rehabilitation hospital, and a response rate of $87.8 \%$ was achieved. The demographic profile of respondents is presented in Table 1. The majority of participants were females 68 (64.8\%). Age ranged from 21 to 45 years, with a mean age of $37.5 \pm 6.3$ years. The majority had a bachelor's degree $93(88.6 \%)$ with a mean years of clinical experience of $12.2 \pm 7.3$. Sixty-five (61.9\%) participants were nurses.

The possible score of the PUKT ranges from 0 to 47 . The mean score of correct answers for all participants was $34.1(71.5 \%)(\mathrm{SD}= \pm 4.8$, Min-Max $=18-44)$. Only 77(73.3\%) of participant had a mean percentage score of $\geq 70 \%$.

The statistical analysis of the participants' demographics using ANOVA revealed that there was no significant relationship between participants' means knowledge scores of PUs prevention and their education level, or years of clinical experience. In contrast, age and profession had a significant relationship with participants' mean knowledge of PUs prevention $(\mathrm{P}<0.001), \quad(\mathrm{P}<0.001)$ respectively (Table 2).

The lowest possible score (negative attitudes) in the attitudes, section was 11 with a highest possible score of 55. The participants demonstrated unsatisfactory attitudes towards PUs prevention. The mean attitudes score was $30.5(56.5 \%)(\mathrm{SD}= \pm 4.8, \mathrm{Min}-\mathrm{Max}=19-43)$.

Table 1 Demographic Characteristics of Participants

\begin{tabular}{ll}
\hline Characteristics & Number of Participants (\%) \\
\hline Mean age years & $37.5 \pm 6.3$ \\
Median age years & $35.0[21-45]$ \\
Profession & \\
Nurse & $65(61.9)$ \\
OT & $19(18.1)$ \\
PT & $14(13.3)$ \\
PMR & $7(6.7)$ \\
Education level & \\
Diploma & $2(1.9)$ \\
Bachelor & $93(88.6)$ \\
Masters & $3(2.9)$ \\
Ph.D. & $7(6.7)$ \\
Mean years of clinical experience & $12.2 \pm 7.3$ \\
Median years of clinical experience & $10.2[1-25]$
\end{tabular}

Data are presented either as mean $( \pm \mathrm{SD})$, median [Min-Max] or actual numbers (\%). OT: occupational therapists PMR: Physical Medicine in Rehabilitation

PT: physical therapists
Table 2 Mean knowledge score according to the geneal characteristics of personal profile

\begin{tabular}{|c|c|c|}
\hline & Knowledge & $\mathrm{p}$ - value \\
\hline & Mean (\%) & \\
\hline Overall & $34.1(71.5)$ & - \\
\hline Profession & & $<0.001$ \\
\hline PMR & $37.2(79.3)$ & \\
\hline Nursing & $35.2(75.0)$ & \\
\hline OT & $33.6(71.7)$ & \\
\hline PT & $27.5(58.5)$ & \\
\hline Age (years) & & $<0.001$ \\
\hline 30 & 37.7 (80.4) & \\
\hline$>30$ & $32.9(70.0)$ & \\
\hline Education level & & 0.092 \\
\hline Bachelor & $33.8(72.1)$ & \\
\hline Diploma & $36.0(77.0)$ & \\
\hline Masters & $31.6(63.0)$ & \\
\hline Ph.D. & $37.2(79.3)$ & \\
\hline Years of clinical experience & & 0.323 \\
\hline 10 & $34.9(74.3)$ & \\
\hline$>10$ & $33.6(71.6)$ & \\
\hline
\end{tabular}

Data are presented as mean and mean score percentage

OT: occupational therapists

PMR: Physical Medicine in Rehabilitation

PT: physical therapists

The results presented in Table 3 revealed that 101 (98.1\%) participants are concerned about PUs prevention in their practices. While, 11 (10.7 \%) participants reported that PUs prevention is a time consuming procedure. Furthermore, two (1.9 \%) participants reported that PUs treatment is a greater priority than PUs prevention. Only seven $(6.8 \%)$ participants showed less interest in PUs prevention than other aspects of care.

Approximately $95.1 \%$ of participants agreed that PUs could be avoided. Moreover, 100 (95.1\%) participants agreed that PUs risk assessment must be regularly carried out on all patients during their stay in hospital.

Our results indicate that PTs were the least interested among 'other' professionals in PUs prevention than other aspects of patient care and that PUs prevention is a low priority for them $(\mathrm{p}<0.001),(\mathrm{p}<0.001)$ respectively. While nurses and OTs reported that their clinical judgment is better than PUs risk assessment in comparison to other areas of care $(P=0.041)$. Moreover, the study showed that there was no significant relationship between participants' attitudes towards PUs prevention and their education level, years of clinical experience, and age (Table 4). 
Table 3 Participant's attitudes towards pressure ulcer prevention

\begin{tabular}{|c|c|c|}
\hline & Agreed $n(\%)$ & Disagreed $n(\%)$ \\
\hline All patients are at potential risk of developing pressure ulcers & $74(71.8)$ & $29(28.2)$ \\
\hline Pressure ulcer prevention is time consuming for me to carry out & $11(10.7)$ & $92(89.3)$ \\
\hline In my opinion, patients tend not to get as many pressure ulcers nowadays & $52(50.5)$ & $51(49.5)$ \\
\hline I do not need to concern myself with pressure ulcer prevention in my practice & $2(1.9)$ & $101(98.1)$ \\
\hline Pressure ulcer treatment is a greater priority than pressure ulcer prevention & $2(1.9)$ & $101(98.1)$ \\
\hline Continuous assessment of patients will give an accurate account of their pressure ulcer risk & $101(98.1)$ & $2(1.9)$ \\
\hline Most pressure ulcers can be avoided & $98(95.1)$ & $5(4.9)$ \\
\hline I am less interested in pressure ulcer prevention than other aspects of care & $7(6.8)$ & $96(93.2)$ \\
\hline My clinical judgment is better than any pressure ulcer risk assessment tool available to me & $8(7.8)$ & $95(92.2)$ \\
\hline In comparison with other areas of care, pressure ulcer prevention is a low priority for me & $5(4.9)$ & $98(95.1)$ \\
\hline Pressure ulcer risk assessment should be regularly carried out on all patients during their stay in hospital & $100(97.1)$ & $3(2.9)$ \\
\hline
\end{tabular}

Data are presented as number and percentage.

\section{Discussion}

Adequate knowledge about PUs prevention is crucial for health care staff. Such knowledge will help frame the decision of whether or not the patient is at higher risk and need prevention. It will also assist in knowing what type of prevention should be used, and how should it be practiced. Although scientific advances in health care guidelines and recommendations for PUs prevention are available, the problem is still widespread in health care facilities around the world. This study aimed to assess the current knowledge and attitudes of the health professionals towards PUs prevention in an acute rehabilitation hospital at KFMC.

The results of this study reveal that the knowledge of participants concerning PUs prevention was average. We used $a \geq 70 \%$ cut-off point to identify participants having sufficient knowledge; at this cut-off point, 77(73.3\%) participants met the criterion. A greater cut-off point would have led to more participants being considered not having adequate knowledge, which highlights the need to update the health professional's knowledge on current guidelines and recommendations for PUs

Table 4 General characteristics of personal profile affecting attitudes of participants

\begin{tabular}{|c|c|c|c|c|}
\hline Items & Variables & Agreen (\%) & Disagreen (\%) & $p$ - value \\
\hline \multirow[t]{5}{*}{ I am less interested in pressure ulcer prevention than other aspects of care } & Profession & & & $<0.001$ \\
\hline & Nursing & $0(0.0)$ & $64(66.7)$ & \\
\hline & OT & $3(42.9)$ & $15(15.6)$ & \\
\hline & PMR & $0(0.0)$ & $7(7.3)$ & \\
\hline & PT & $4(57.1)$ & $10(10.4)$ & \\
\hline \multirow[t]{5}{*}{ My clinical judgment is better than any pressure ulcer risk assessment tool available to me } & Profession & & & 0.041 \\
\hline & Nursing & $3(37.5)$ & $61(64.2)$ & \\
\hline & OT & $3(37.5)$ & $15(15.8)$ & \\
\hline & PMR & $2(25)$ & $5(5.3)$ & \\
\hline & PT & $0(0.0)$ & $14(14.7)$ & \\
\hline \multirow[t]{5}{*}{ In comparison with other areas of care, pressure ulcer prevention is a low priority for me } & Profession & & & $<0.001$ \\
\hline & Nursing & $0(0.0)$ & $64(65.3)$ & \\
\hline & OT & $1(20)$ & $17(17.3)$ & \\
\hline & PMR & $0(0.0)$ & $7(7.1)$ & \\
\hline & PT & $4(80)$ & $10(10.2)$ & \\
\hline
\end{tabular}

Data are presented as number and percentage

OT: occupational therapists

PMR: Physical Medicine in Rehabilitation

PT: physical therapists 
prevention. The mean percentage score of correct answers was $71.5 \%$ for all participants, $79.3 \%$ for PMRs, 75.0 \% for nurses, 71.7 \% for OTs, and $58.5 \%$ for PTs. It was noted from our results that nurses showed good mean percentage score of correct answers; this is especially important as good knowledge and practice of nurses have its own significant contribution for decreasing prevalence of PUs; because, even if the prevention of PUs is a multidisciplinary responsibility, usually nurses play a major role in PUs prevention. Likewise, a study conducted by Pieper et al, using the same knowledge scale showed that the mean percentage of correct answers by 75 intensive care unit nurses from two American hospitals was $71.3 \%$ [16]. In the United States, a study of nurses from Montana used the preliminary version of the Pieper's PUKT; found that the percentage of correct answers was $78 \%$ [17]. While some studies have showed a good level of knowledge (70-80 \%) among nurses [18-22], others have shown limited knowledge with only $\leq 50 \%$ of nurses knowing half of the recommendations [1, 23, 24]. Similarly, a study conducted in Bangladesh indicated that the overall nurses' knowledge on PUs prevention was found to be $57.79 \%$ [25]. In Alexandria, Egypt, a study conducted by Enein et al. in one of the largest health insurance hospital showed that, the overall mean percentage score for nurses were below the minimum acceptable level [26], which would be explained by lack of learning resources for nurses to update their knowledge.

Younger age group participants significantly have higher mean of knowledge scores than older age group, however no significant relationship between participants' mean of knowledge scores of PUs prevention and their education level or years of clinical experience was found. The findings are comparable to Pieper and Mott who did not find any association between educational level and knowledge $[15,27]$. Knowledge on PUs prevention and treatment were known to be affected by certain individual and educational characteristics as revealed by studies on nurses and nursing students' $[11,16]$.

Attitude is considered an essential individual characteristic as it determines individual expectations [28]. Ajzen and Fishbein stated in their study that an individual's likelihood of carrying out a positive behavior is influenced by a positive attitude [29]. This statement is supported by Champion, Leach and Hicks who showed the positive impact of more positive attitudes on the quality of nursing practice [30, 31].

In this study, the participants demonstrated unsatisfactory attitudes towards PUs prevention with a mean attitude score of 30.5(56.5\%). A study conducted by Beeckman et al. [32], about the knowledge and attitudes of nurses towards PUsprevention in a Belgian hospital showed that the knowledge of nurses about PUs prevention was poor and only half of the nurses showed attitudes scores of equal to or greater than $75 \%$ with a mean attitude score of $71.3 \%$ [32]. In addition, our results showed that11 (10.7\%) of participants believe that PUs prevention is a time consuming procedure and among the health care professionals, nurses and OTs reported that that their clinical judgment is better in other areas of health care than use of available PUs risk assessment tool.

As PUs development during hospitalization is an important healthcare quality indicator, the adoption of a useful prevention system could eliminate the problem. Successful PUs prevention depends on health professionals' knowledge and attitudes, especially for health professionals who provide direct patient care. It is necessary to understand that individual factors are known to influence a health care professionals' knowledge, attitudes, and the use of evidence-based practice; hence, there is an urgent need for rehabilitation hospitals around Saudi Arabia to formulate strategies and relevant policies in order to combat the socio-economic burden of this problem. The results of this study could be used as a guide for making a strategic plan directed at adopting preventative measures for PUs that can improve the quality of health care services largely. We would recommend that a further follow up on research looking into ways to make the best use of education for the health professionals working in this critical area is carried out.

\section{Conclusions}

The present study assessed the current knowledge and attitudes of health professionals regarding PUs prevention in an acute rehabilitation hospital. The majority of participants had an average level of knowledge about PUs prevention; they exhibited unsatisfactory attitudes towards PUs prevention. Increased health professionals awareness may improve their attitudes towards PUs prevention.

\section{Abbreviations \\ PUs: Pressure Ulcers; KFMC: King Fahad Medical City; PUKT: Pressure Ulcer Knowledge Test; OT: occupational therapists; PMR: Physical Medicine in Rehabilitation; PT: physical therapists.}

\section{Competing interests}

The author(s) declare that they have no conflict of interests.

\section{Authors' contribution}

BK, AKA and MAA carried out the study, and participated in its design. AKA and BK conceived the study, and acquisition of data, wrote the manuscript. Meanwhile, MAA and BK participated in interpretation of data, drafting the article and revising it critically for important intellectual content. All authors read and approved the final manuscript.

\section{Acknowledgements}

The authors wish to thank Ms. Jenny Gray for her assistance and linguistic review for this study. 


\section{Author details}

Ambulatory Care Centre, Executive Administration of Nursing Services, King Fahad Medical City, Riyadh, Saudi Arabia. ${ }^{2}$ Research Center, King Fahad Medical City, P.O Box 5904611525 Riyadh, Saudi Arabia.

\section{Received: 13 September 2015 Accepted: 24 February 2016}

\section{0.70}

\section{References}

1. Nuru N, Zewdu F, Amsalu S, Mehretie Y. Knowledge and practice of nurses towards prevention of pressure ulcer and associated factors in Gondar University Hospital, Northwest Ethiopia. BMC Nurs. 2015;14:34

2. Gedamu H, Hailu M, Amano A. Prevelence and associated factors of pressure ulcer among hospitalized patients at Felegehiwot Referal Hospital Bahir Dar, Ethiopia. Advances in Nursing. 2014;1-8.

3. Pieper B. Mechanical Forces: Pressure, Shear and Friction. In: R. Bryant R, Nix D, editors. Acute and chronic wounds: Current Management Concepts. St. Louis, Mo.: Mosby: Elsevier; 2007. p. 205-34.

4. Bours GJ, Halfens RJG, Huyer Abu-Saad H, Grol RT. Prevalence, prevention and treatment of pressure ulcers: descriptive study in 89 institutions in the Netherlands. Res Nurs Health. 2002;25:99-110.

5. Hulsenboom M, Bours G, Halfens R. Knowledge of pressure ulcer prevention: a cross-sectional and comparative study among nurses. BMC Nursing. 2007:9:6-2.

6. Suriadi, Sanada H, Sugama J, Kitagawa A, Thigpen B, Kinosita S, et al. Risk factors in the development of pressure ulcers in an intensive care unit in Pontianak, Indonesia. Int Wound J. 2007:4:208-15.

7. Lindbloom E, Brandt J, Hough L, Meadows S. Elder Mistreatment in the Nursing Home: A Systematic Review. J Am Med Dir Assoc. 2007:8:610-6.

8. Gupta N, Loong B, Leong G. Comparing and contrasting knowledge of pressure ulcer assessment, prevention and management in people with spinal cord injury among nursing staff working in two metropolitan spinal units and rehabilitation medicine training specialists in a three-way comparison. Spinal Cord. 2012;50:159-64.

9. Hopkins A, Dealey C, Bale S, Defloor T, Worboys F. Patient stories of living with a pressure ulcer. J Adv Nurs. 2006;56:345-53.

10. Gunningberg L. Pressure ulcer prevention: evaluation of an education programme for Swedish nurses. J Wound Care. 2004;13:85-9.

11. Pancorbo-Hidalgo P, García-Fernández F, López-Medina I, López-Ortega J. Pressure ulcer care in Spain: nurses? knowledge and clinical practice. J Adv Nurs. 2007;58:327-38.

12. Källman U, Suserud B. Knowledge, attitudes and practice among nursing staff concerning pressure ulcer prevention and treatment - a survey in a Swedish healthcare setting. Scand J Caring Sci. 2009;23:334-41.

13. Moore Z, Price P. Nurses' attitudes, behaviours and perceived barriers towards pressure ulcer prevention. J Clin Nurs. 2004;13:942-51.

14. Maylor M, Torrance C. Pressure sore survey. Part 2: nurses' knowledge. Int Wound J. 2007:8:49-52.

15. Rodgers S. A study of the utilization of research in practice and the influence of education. Nurse Educ Today. 2000;20:279-87.

16. Pieper B, Mattern JC. Critical care nurses' knowledge of pressure ulcer prevention, stating and description. Ostomy Wound Manage. 1997:43:22-31.

17. Zulkowski K, Ayello E, Wexler S. Certification and Education. Adv Skin Wound Care. 2007:20:34-8

18. Bostrom J, Kenneth H. Staff nurse knowledge and perceptions about prevention of pressure sores. Dermat Nurs. 1992:4:365-7.

19. Beitz JM, Fey J. Perceived need for education vs. actual knowledge of pressure ulcer care in a hospital nursing staff. Med Surg Nurs. 1998;7:293301.

20. Provo B, Piacentine L, Dean-Barr S. Practice versus knowledge when it comes to pressure ulcer prevention. J Wound Ostomy Continence Nurs. 1997;24:265-9.

21. Russell L. Knowledge and practice en pressure area care. Prof Nurse. 1996; 11:301-6.

22. Anthony D, Mockridge J. Nurses' knowledge about pressure sore treatment and healing. Nurs Stand. 1999;13:68-71.

23. Egglink M, Halfens RJ. Knowledge, beliefs and use of nursing methods in preventing pressure sores in Dutch hospitals. Int J Nurs Stud. 1995;32:16-26.

24. Rengin A, Merdiye S. Pressure ulcer prevention and management strategies in Turkey. J Wound Ostomy Continence Nurs. 2005;32:230-7.
25. Islam S. Nurses' Knowledge, Attitude, and Practice regarding Pressure Ulcer Prevention for Hospitalized Patients at Rajshahi Medical College Hospital in Bangladesh. 2010

26. Enein NYAE, Zaghloul AA. Nurses' knowledge of prevention and management of pressure ulcer at a Health Insurance Hospital in Alexandria. Int J Nurs Pract. 2011;17:262-8.

27. Pieper B, Mottern M. Nurses' knowledge of pressure ulcer prevention, staging, and description. Adv Wound Care. 1995;8:34-40.

28. Petty R, Cacioppo J. Attitudes and persuasions: classic and contemporary approaches. Boulder, CO: Westview Press; 1996. 3-37.

29. Ajzen I, Fishbein M. The influence of attitudes on behavior. In: Albarracín D, Johnson BT, Zanna MP, editors. The handbook of attitudes. Mahwah, NJ: Erlbaum; 2005. p. 173-221.

30. Champion V, Leach A. Variables related to research utilization in nursing: An empirical investigation. J Adv Nurs. 1989;14:705-10.

31. Hicks C. A study of nurses' attitudes towards research: a factor analytic approach. J Adv Nurs. 1996:23:373-9.

32. Beeckman D, Defloor T, Schoonhoven L, Vanderwee K. Knowledge and Attitudes of Nurses on Pressure Ulcer Prevention: A Cross-Sectional Multicenter Study in Belgian Hospitals. Worldviews Evid Based Nurs. 2011;8: $166-76$

\section{Submit your next manuscript to BioMed Central and we will help you at every step:}

- We accept pre-submission inquiries

- Our selector tool helps you to find the most relevant journal

- We provide round the clock customer support

- Convenient online submission

- Thorough peer review

- Inclusion in PubMed and all major indexing services

- Maximum visibility for your research

Submit your manuscript at www.biomedcentral.com/submit
Biomed Central 